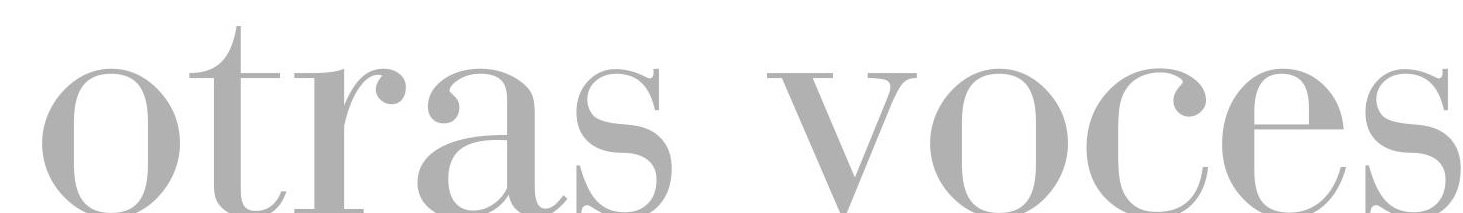





\title{
Ausência de Humanização na "Revitalização" do Centro Histórico de Florianópolis, Santa Catarina, Brasil
}

\author{
Krisciê Pertile Perini ${ }^{1}$ \\ Universidade Federal de Santa Catarina (UFSC), Brasil \\ krisciepertile@gmail.com \\ Marcos Sardá Vieira ${ }^{2}$ \\ Universidade Federal da Fronteira Sul (UFFS) \\ marcosarda@gmail.com \\ Julia Silvia Guivant ${ }^{3}$ \\ Universidade Federal de Santa Catarina (UFSC) \\ juliaguivant@gmail.com \\ Recibido: 24 de enero de 2017 \\ Aceptado: 13 de junio de 2017 \\ Disponible en línea: 30 de junio de 2108
}

\footnotetext{
1 Doutoranda pelo Programa Interdisciplinar em Ciências Humanas da Universidade Federal de Santa Catarina (UFSC). Integrante do Instituto de Pesquisa em Riscos e Sustentabilidade (IRIS/UFSC). Docente do Instituto de Ciências Humanas da Universidade Federal do Rio Grande (FURG) (Brasil).

2 Doutorando pelo Programa Interdisciplinar em Ciências Humanas da Universidade Federal de Santa Catarina (UFSC) com investigação relacionando às áreas de Gênero e Espaço. Arquiteto, urbanista e docente da Universidade Federal da Fronteira Sul (UFFS) (Brasil).

3 Doutora. Docente do Departamento de Sociologia e Ciência Política e do Programa de Doutorado Interdisciplinar em Ciências Humanas, Universidade Federal de Santa Catarina (Brasil). Coordenadora do Instituto de Pesquisa em Riscos e Sustentabilidade (IRIS/UFSC) (Brasil).
} 


\title{
Ausencia de Humanización en la revitalización del centro histórico de Florianópolis - Santa Catarina - Brasil
}

\section{Resumen}

Este artículo presenta el contexto actual de transformación urbana del área central e histórica de Florianópolis (Santa Catarina, Brasil), como medida de control social y explotación del potencial turístico e inmobiliario. Para comprender este proceso se consideran los conceptos de "revitalización" y "humanización" a partir del análisis del proyecto "Feria Permanente Viva la Ciudad", desarrollado por la Alcaldia Municipal en asociación con la Cámara de Comercio (CDL). En la discusión de esta problemática sobre reforma urbana, ante el interés por la revitalización de esta área degradada, consideramos que la prerrogativa de fomentar actividades de cultura y ocio como instrumento gradual de apropiación del espacio público, surge para atender intereses particulares de especulación, utilizando el concepto de "revitalización" como justificación para el control territorial. Por otro lado, la necesidad de incluir el concepto de "humanización", volcada hacia los intereses públicos y sociales, sería una alternativa más democrática en la reformulación de la función de los espacios públicos, sin transformarlos en meros receptáculos de la espectacularización y del consumo.

Palabras clave: proyecto "Feira Permanente Viva a Cidade"; Florianópolis; Humanización; Espacio Público

\section{Absence of humanization in the revitalization of Florianopolis' historical center, Santa Catarina - Brazil}

\begin{abstract}
This article presents the current context of urban transformation of the central and historical area of Florianopolis (Santa Catarina, Brazil), as a measure of social control and exploitation of tourism and real state potential. The concepts of "revitalization" and "humanization" are taken in consideration after analyzing the Live the City Permanent Fair project developed by the City Hall in association with the Chamber of Commerce (CDL). In the discussion on urban reform and due to the interest in revitalizing this degraded area, we consider that the prerogative of promoting culture and leisure activities -as a gradual instrument of appropriation of public space- addresses speculative interests by using the concept of "revitalization" as a justification for territorial control. On the other hand, the need to include the concept of "humanization", focused on public and social interests, would turn to be a more democratic alternative in the reformulation of the function of public spaces, without transforming them into mere receptacles of spectacularization and consumption. Keywords: Feira Permanente Viva a Cidade project; Florianopolis; humanization; public space.
\end{abstract}

\section{Ausência de Humanização na "Revitalização" do Centro Histórico de Florianópolis, Santa Catarina, Brasil \\ Resumo}

Este artigo apresenta o contexto atual de transformação urbana da área central e histórica de Florianópolis (Santa Catarina, Brasil), como medida de controle social e exploração do potencial turístico e imobiliário. Para compreender este processo são considerados os conceitos de "revitalização" e "humanização" a partir da análise do projeto "Feira Permanente Viva a Cidade", desenvolvido pela Prefeitura Municipal em parceria com a Câmara de Dirigentes Lojistas (CDL). Na discussão desta problemática de reforma urbana, diante do interesse pela revitalização desta área degradada, consideramos que a prerrogativa de fomentar atividades de cultura e lazer como instrumento gradual de apropriação do espaço público surge para atender interesses particulares de especulação, utilizando o conceito de "revitalização" como justificativa para o controle territorial. Por outro lado, a demanda pelo conceito de "humanização", voltada para os interesses públicos e sociais, seria uma alternativa mais democrática na reformulação da função dos espaços públicos, sem transformá-los em meros receptáculos da espetacularização e do consumo.

Palavras-chave: projeto "Feira Permanente Viva a Cidade"; Florianópolis; humanização; espaço público 


\section{Introdução}

A realidade dos interesses especulativos sobre os territórios urbanos, justificado pelo desejo de modernização das cidades, acontece desde o final do século XIX e início do século XX e pode estar associado, na escala local e no tempo atual, com as intervenções urbanas de iniciativa privada sobre o espaço público, que procuram transformar áreas previamente degradadas pela ineficácia do planejamento urbano integral. Este tipo de intervenção, também denominada "revitalização", torna-se uma mudança válida sob a justificativa de implantar qualidade de vida para os visitantes e moradores fixos envolvidos como público alvo de interesse do mercado econômico.

Analisando estas medidas de transfomaçao urbana, apresentamos neste artigo o projeto "Feira Permanente Viva a Cidade", desenvolvido em Florianópolis, capital do estado de Santa Catarina/ Brasil (figura 1), fruto de uma parceria entre a Prefeitura Municipal e a Câmara de Dirigentes Lojistas do município (CDL Florianópolis). Este projeto surge com a intenção de revitalizar a área central da cidade, que foi preterida pelo planejamento urbano desde a década de 2000, apesar da sua boa localização, inclusive enquanto parte do Centro Histórico (figura 2).

Porém, uma vez que a revitalização do espaço público não contempla obras físicas substanciais para melhorias na infraestrutura urbana, poderíamos dizer que as intenções de revitalização no centro histórico de Florianópolis atendem aos interesses públicos e patrimoniais? As intervenções em áreas públicas promovidas pelo Estado e com apoio da iniciativa privada, como no caso do projeto "Feira Permanente Viva a Cidade", seriam um instrumento de longo prazo para a gentrificação e o enobrecimento das áreas urbanas centrais na Ilha da Magia?

Refletindo sobre estas questões, o objetivo do artigo é analisar a intervenção espacial do projeto implantado no centro histórico de Florianópolis, quanto ao seu discurso e práticas em defesa da revitalização urbana. 


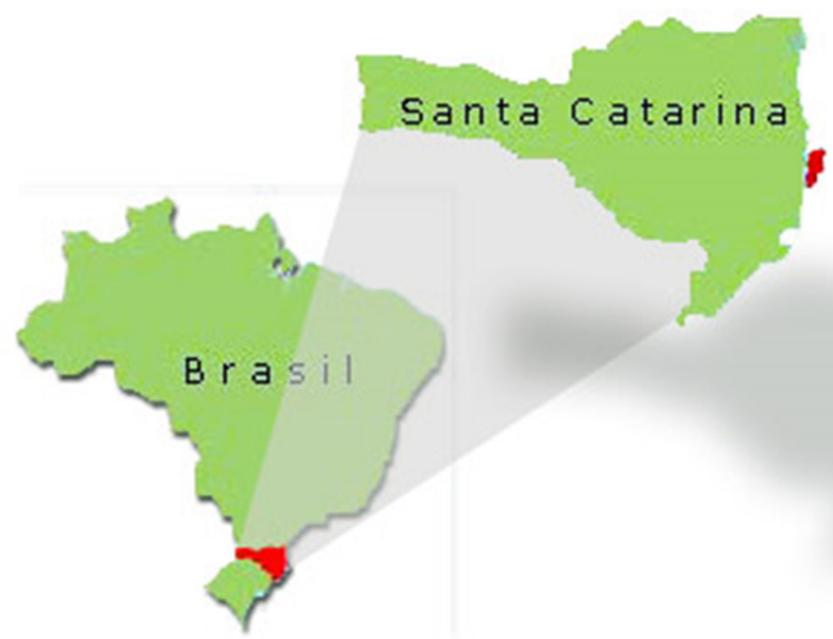

Figura 1. Estado de Santa Catarina e Florianópolis no contexto geográfico brasileiro Fonte: disponivel em http://www.intern-brazil.com/wp-content/uploads/2014/08/sc-no-mapa-do-Brasil-300x203.jpg

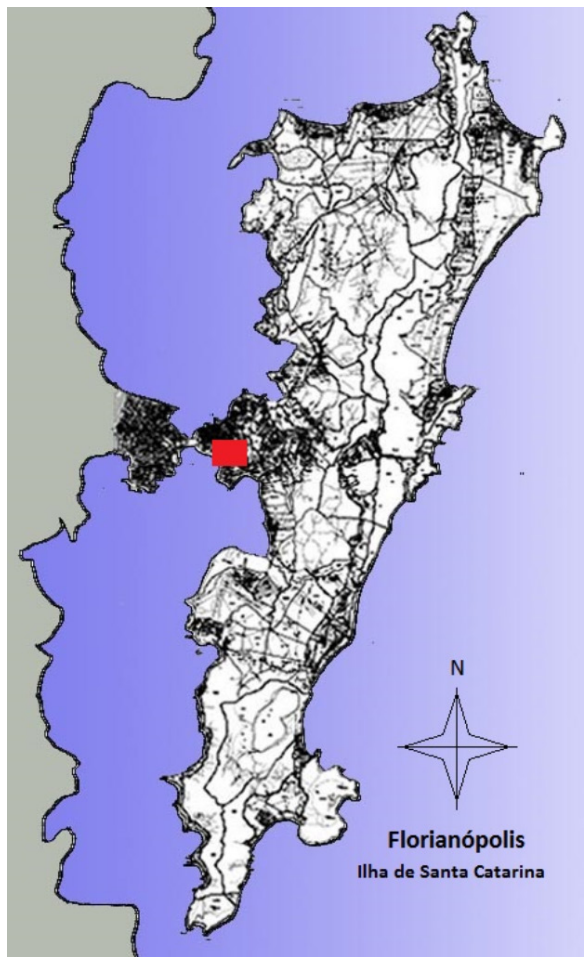

Figura 2. Localização do projeto "Feira Permanente Viva a Cidade" no Centro Histórico de Florianópolis Fonte: Imagem dos autores, 2013. 
A metodologia de construção desta pesquisa baseia-se no referencial histórico da conformação urbana de Florianópolis, ao longo de suas principais obras públicas para caracterizar as feições de uma capital moderna; e no referencial teórico para a compreensão dos conceitos de revitalização e humanização em áreas urbanas.

Através de fontes secundárias são analisadas informações sobre a implantação do projeto em questão, além de visitas in loco realizadas entre os meses de junho e julho de 2015 durante a promoção dos eventos na área de estudo, ocasiões em que fizemos uso do método de observação incorporada e participativa.

$\mathrm{Na}$ sequência, são apresentadas considerações sobre a sutileza na demarcação e no controle territorial sobre espaços tidos como públicos, destacando o caráter efêmero e sutil dos possíveis estágios para a consolidação de novas territorializações urbanas.

\section{Conformação urbana em Florianópolis}

As grandes intervenções nas cidades brasileiras, promovidas durante a Primeira República (1889-1930), tiveram como referência as grandes reformas urbanas europeias ocorridas no final do século XIX, a exemplo da reforma de Paris e Viena, "que lançaram as bases legais para o mercado imobiliário capitalista, promovendo a valorização imobiliária" (Agostinho, 2008, p. 117) e, consequentemente, a reativação e incremento do comércio, o que acarretou processos de segregação social.

Durante este período de reformas nas principais cidades brasileiras (São Paulo/SP, Belém/PA, Porto Alegre/RS, Recife/PE, entre outras) foram executadas obras importantes para estabelecer a infraestrutura urbana de modernização no país, como os sistemas de transporte, o saneamento básico e o embelezamento dos logradouros através da pavimentação, acréscimo de mobiliário urbano e plantio de vegetação. Estes melhoramentos para a configuração das cidades também estavam vinculados à estratégia de controle social, segregando as classes mais pobres 
na apropriação das áreas mais valorizadas através das reformas, disciplinando e condicionando a vida da população em geral de maneira a construir um corpo social condizente com os ideais da modernidade e as expectativas de um perfil humano ideal (Sêga, 2000).

Durante o século XIX e início do século XX, o litoral catarinense, incluindo a região atual da Grande Florianópolis, pouco se desenvolveu industrialmente, diferentemente de outras regiões e municípios catarinenses que obtiveram amplo crescimento industrial no mesmo período, a exemplo de Joinville e Blumenau. Apesar de existir uma grande expectativa para o crescimento de Florianópolis, a cidade permaneceu pequena, com a economia baseada no comércio local, na administração pública, na produção de subsistência e com pouca expressão nacional ao longo das décadas de 1930 e 1940.

Tal período foi considerado de estagnação para o desenvolvimento urbano florianopolitano, devido ao recorrente declínio do transporte e comércio por via marítima desde o final do século XIX. Por isso, no decorrer do século XX, criou-se uma ideia de atraso para o desenvolvimento da capital de Santa Catarina em relação a outras cidades brasileiras mais modernizadas, tendo como principal referência, na época, o desenvolvimento do Rio de Janeiro (Pimenta, 2005; Agostinho, 2008; Costa, 2011).

A intenção de manter Florianópolis como capital do estado foi um aspecto importante na promoção das reformas urbanas ocorridas na segunda metade do século XX. As definições de suas feições para uma verdadeira capital através de obras públicas de saneamento e na maior vinculação da ilha com a região continental surgiram com o interesse de reforçar o discurso de desenvolvimento nacional e garantir a influência do poder oligárquico catarinense.

Diante das propostas de desenvolvimento da cidade, foram implantadas medidas legais de reforma urbana que viabilizaram a privatização dos interesses públicos, em um movimento conservador, lento e tradicional para a modernização da cidade. Esta configuração de modernidade se torna efetiva a partir da década de 1960, com 
a construção dos aterros na Baía Sul, da Avenida Beiramar Norte, construção da Ponte Colombo Sales (finalizada em 1975), a implantação da Universidade Federal de Santa Catarina e a consolidação dos principais eixos viários para estabelecer a comunicação formal da capital catarinense com o interior do estado, através da BR-101 e da SC-282 (Agostinho, 2008).

Neste panorama, o centro histórico florianopolitano se transformou em um espaço fragmentado e de pouco interesse imediato para o mercado imobiliário, que descobria outras áreas de ocupação nos territórios da Ilha e do Continente. Apesar deste cenário de expansão urbana, o centro da cidade manteve seu caráter de cidade média ao longo do século $\mathrm{XX}$, atendendo a demanda local para as necessidades do comércio e serviços, mantendo preservados o conjunto de casarios antigos e as principais referências de sua paisagem urbana, a saber: a Praça XV de Novembro, o Largo da Alfandega e o Mercado Público, próximos aos eixos comerciais.

Concordamos com Nelson Popini Vaz quando este afirma que mais do que caracterizar a área simplesmente como "centro urbano", onde se dá grande parte das funções relacionadas a uma cidade, cabe ao centro de Florianópolis o conceito de "área central", ou seja, o coração histórico da capital catarinense, "conjunto mais importante da área urbana no período que antecede a modernização" ${ }^{4}(1990$, p. 16). Entendemos que tal denominação também diz respeito à delimitação das áreas públicas de uso coletivo e aos espaços urbanos de comunicação interpessoal.

Assim, o Centro Histórico de Florianópolis pode ser definido, desde seu início, como um espaço de grande importância para a população, área compreendida como a própria "cidade", abrigando funções importantes, sobretudo o comércio. Nesse sentido representa, ao mesmo tempo, um "espaço vivo" para o convívio da população, mas também uma área estratégica para a reserva de mercado que, historicamente, definiu o cenário de disputas territoriais movidas pelos interesses de coalizão política e, mais recentemente, como sede dos empreendimentos privados.

\footnotetext{
4 Processo acelerado a partir dos anos cinquenta.
} 
Portanto, os processos de reconfiguração urbana em Florianópolis, com o aumento dos fluxos e dos acréscimos tecnológicos, representam novos processos políticos e territoriais na inserção desta cidade latino-americana no âmbito global e contemporâneo de práticas urbanas, privilegiando o espaço privado e tornando mais complexa a delimitação (e quase inexistência) do espaço público (Portal, 2016).

\section{Projeto "Feira Permanente Viva a Cidade"}

Em 2011, a CDL Florianópolis, por meio de um dos seus núcleos de trabalho (Núcleo do Centro Histórico) apresentou a diversos órgãos públicos o projeto, inicialmente denominado "Feira da Luz", que tinha por objetivo a realização da feira comercial, os sábados, na área central da capital catarinense. Tal iniciativa foi apresentada como uma das ações para revitalizar a porção leste do Centro da cidade, entre a Praça XV de Novembro e a Avenida Hercílio Luz (figura 3).

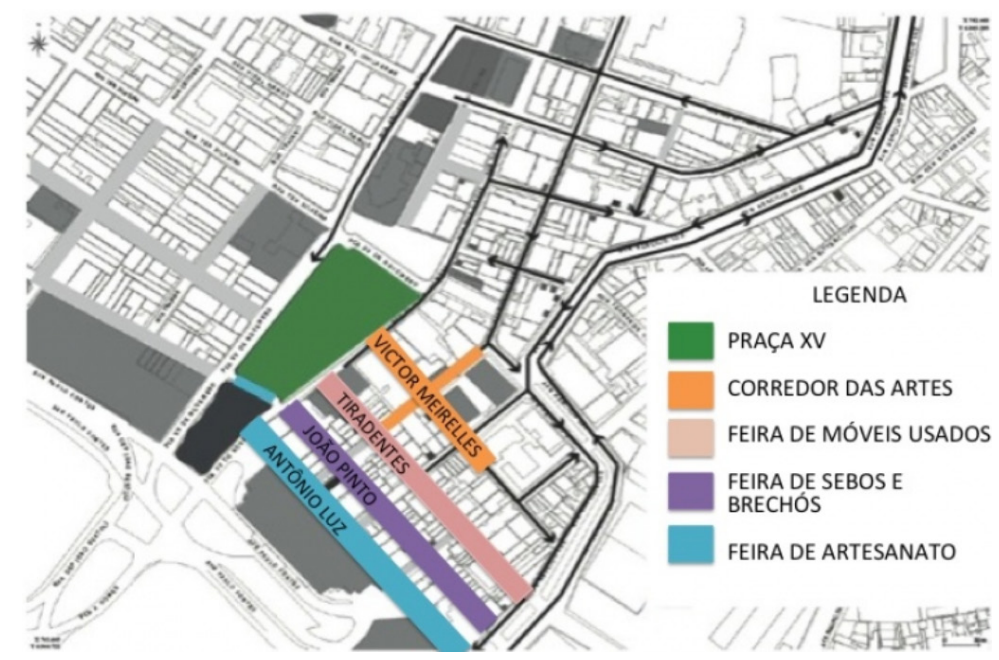

Figura 3. Principais ruas e pontos de referência do projeto "Feira Permanente Viva a Cidade" no Centro Histórico (mapa sem escala)

Fonte: Site Bicicleta na Rua. Disponivel em: https://bicicletanarua.files.wordpress. com/2013/08/viva-a-cidade-mapa.jpg 
Em julho de 2014, o projeto sofreu alterações e passou a denominar-se "Feira Permanente Viva a Cidade", fruto de uma parceria entre Prefeitura Municipal ${ }^{5}$ e CDL Florianópolis, com patrocínio da Koerich Imóveis. Esta última trata-se de uma empresa fundada em 1993 que representa quatro construtoras. Em seu site é possivel encontrar um discurso a respeito do "[...] cuidado de adotar praças, realizar intervenções de recuperação e apoiar projetos que atuam em diversas comunidades [...]" (Koerich Imóveis, 2017, s/p). As intenções parecem ir ao encontro do que expõe Leite (2005), quando afirma que para além da conservação de espaços públicos, há um crescente interesse do setor privado na transformação de espaços possuidores de bens simbólicos, como é o caso de centros históricos, em mercadoria cultural, sujeitos à racionalidade econômica das trocas.

O projeto que ocorria aos sábados, nas ruas Saldanha Marinho, Nunes Machado, Travessa Ratcliff, Antônio Luz, João Pinto, Tiradentes e Victor Meirelles, abarcou diversas atividades comerciais, dentre elas o artesanato, a venda de antiguidades, brechós, sebos e gastronomia. De acordo com a notícia publicada no site da Câmara de Dirigentes Lojistas, "o objetivo inicial do projeto [foi] humanizar os espaços públicos, sua arquitetura e todo mobiliário urbano, transformando o local numa grande região de bem-estar, valorizando inclusive o comércio estabelecido" (CDL Florianópolis, 2013, s/p).

$\mathrm{Na}$ ocasião, o superintendente do Instituto de Planejamento Urbano de Florianópolis (IPUF) e Secretário de Meio Ambiente e Desenvolvimento Urbano, Dalmo Vieira Filho, disse compreender a cidade como um organismo vivo, um artefato cultural que necessita de "humanização", processo que deve iniciar pelo Centro por se tratar da "sala de estar" da cidade, local utilizado por moradores e visitantes (Frighetto, 2013). Na reprodução do discurso promovido pela Prefeitura e pelos comerciantes, o verdadeiro conceito de urbanismo passa pela convivência, pela valorização dos espaços comuns e pelas vivências na e $d a$ cidade.

5 Outras instituições envolvidas no projeto: Secretaria de Meio Ambiente e Desenvolvimento Urbano, Secretaria de Cultura, Instituto de Geração de Oportunidades de Florianópolis (IGEOF), Secretaria Municipal de Turismo (SETUR), Secretaria Municipal da Saúde - Vigilância Sanitária, Guarda Municipal, Polícia Militar e Polícia Civil. 
Nesse sentido, o projeto em questão visa o desenvolvimento de atividades que estimulam o uso do espaço público e a sociabilidade, dentre elas cita-se as "praças eventuais", onde ruas são fechadas para o fluxo de veículos em determinado período do dia para que estabelecimentos gastronômicos e de bebidas possam instalar mesas e cadeiras na via e nas calçadas, sem dificultar a circulação dos moradores residentes na região.

Já a "Feira Artes e Usados" aumentou o número de lojas especializadas em antiguidades nos arredores, sobretudo, diante da consolidação do projeto para visibilizar o comércio local. Em sua primeira edição, realizada em 27 de julho de 2013, o projeto "Feira Permanente Viva a Cidade" mobilizou mais de cem comerciantes, o que é atípico para esta localidade urbana.

Na última década, esta porção do centro histórico de Florianópolis foi menos favorecida pelos investimentos públicos e pela manutenção das instalações urbanas de superfície que pudessem agregar valor ao ambiente de domínio público.

A degradação desta porção central foi acelerada, principalmente, após a desativação do antigo terminal de transporte público, substituído pelo terminal do Sistema Integrado de Transporte a partir de 2003, com sua nova implantação nas proximidades da Rodoviária Rita Maria. Esta alteração do centro de mobilidade para o transporte coletivo provocou impacto simultâneo no fluxo de pedestres e, por consequência, na valorização do solo urbano desta área central de Florianópolis. Além de desqualificar os serviços de transporte coletivo (quando comparado ao sistema anterior) e aumentar o número de veículos particulares nas ruas do município, o Sistema Integrado de Transporte gerou prejuízos sistêmicos à mobilidade urbana da cidade, de acordo com a avaliação de Goldner e Silva (2013).

A transformação da área central da capital está diretamente associada às alterações do sistema de circulação (vias e meios de transporte) do Distrito Sede. Nas justificativas apresentadas para 
a implantação do projeto "Feira Permanente Viva a Cidade", com a intenção de revitalizar a área historicamente degradada pelo planejamento urbano anterior, surgem afirmações que se apoiam em termos como "preservar e revitalizar" o local, gerando renda, trabalho e incentivo na participação dos moradores em atividades vinculadas a sociabilidade, principalmente, durante os finais de semana, quando a região tende a ficar mais abandonada pela diminuição do fluxo de pessoas (Camargo, 2014).

Nesse sentido, a ênfase reside no 'valor pragmático' da região, em detrimento ao 'valor afetivo', onde a recuperação do sentimento de pertencimento dos moradores está subjugada pelos valores de uso do espaço, quando deveriam ser desenvolvidos conjuntamente. Para além das atividades culturais propostas, seria essencial determinar quais implicações tais projetos acarretariam na vida dos usuários destes espaços e, de forma mais ampla, na manutenção de seu caráter público (Meneses, 2000).

\section{Revisão das categorias: revitalização e humanização}

Durante a consulta das informações acerca do projeto em questão, observamos que os termos "revitalização" e "humanização" são utilizados de forma recorrente nos discursos da Câmara de Dirigentes Lojistas e da Prefeitura de Florianópolis. ${ }^{6}$ Tais discursos não esclarecem quais são os resultados esperados e, nem mesmo, se haverão detalhes do investimento previsto para a transformação física do espaço público diante das medidas de "revitalização" da área central, justificando a intervenção urbana e o uso de instrumentos e recursos públicos para promover e assegurar seu funcionamento e atividades comerciais.

Tanto a CDL quanto a prefeitura municipal não disponibilizaram dados concisos a respeito do projeto, o qual é divulgado somente por meio de publicações em jornais locais que visam informar moradores e visitantes a cerca da agenda de atividades, e uma página na rede social Facebook, utilizada para o mesmo fim. Esta falta de transparência torna o projeto passível de críticas e questionamentos quanto aos seus reais objetivos para um processo que se diz humanizador desta porção da cidade. 
O uso do termo "revitalizar" faz referência a uma área sem vitalidade. Entretanto, o centro de Florianópolis possui atividades comerciais, serviços, residências e circulação de pessoas, tornando o uso do conceito equivocado para o tratamento de qualquer intervenção neste espaço público.

O sociólogo Rogério Proença Leite apresenta o conceito de "revitalização" utilizando-se do termo "enobrecimento", o que nos parece ir ao encontro da discussão aqui proposta. Afirma que "o termo tem sido usado para designar diferentes formas de intervenção urbana, variando entre os processos de 'regeneração', 'reabilitação', ou 'revitalização' de áreas ou sítios patrimoniais de alto valor histórico" (Leite, 2010, p. 74). Diante disso, dispositivos são empregados em centros históricos com o objetivo de transformá-los em lugares de espetáculo, com forte apelo visual, utilizando-se para tanto da arquitetura e da monumentalidade do patrimônio disponível.

Para o autor, essa pretensão de reativar o espaço público resulta na segregação e fragmentação do espaço em diferentes lugares. Tais políticas de enobrecimento (ou revitalização) tentam higienizar os espaços à medida que vendem ao usuário a ideia de segurança por meio da "vida pública de calçadas seguras e vitrines lustrosas, quase numa espécie de nostalgia de uma belle époque perdida" (Leite, 2010, p. 75). A modalidade de enobrecimento predominante no Brasil visa o apelo turístico em detrimento da recuperação de residências de população de baixa renda que, por ventura, permanecessem nestes locais. Assim, da mesma forma que pretendem enobrecer a visitação, também almejam e contribuem para a gentrificação das áreas de centralidade urbana (Leite, 2010).

Leite $(2010$, p. 76$)$ afirma ainda que os centros históricos costumam passar por três etapas de "revitalização", a saber:

[...] iniciam com a plena existência do centro como estrutura funcional da vida urbana que agrega as primeiras manifestações de uma cultura urbana. Em um segundo momento, por vários fatores relacionados com a crescente urbanização, eles perdem sua importância socioeconômica, sendo estigmatizados e desvalorizados 
socialmente. Numa etapa seguinte, reclamam e adquirem identidade patrimonial, reinserindo-se na pauta das políticas urbanas.

Dessa forma as políticas de enobrecimento se estabelecem por meio da instalação de serviços, antes inexistentes e/ou precários, ancoradas em um discurso que ressalta a depreciação dos aspectos simbólicos e a degradação da estrutura física local, ainda que historicamente tais espaços mantenham elementos de representação material importantes para a cidade.

Para Paola Jacques (2005) a revitalização nada mais é do que uma estratégia de marketing urbano, que busca construir uma marca na e da cidade, garantindo sua inserção nas redes internacionais sob o intuito de aumentar a demanda turística.

Assim, há uma dualidade entre as ações voltadas para o espetáculo e aquelas que atendem a demanda de participação popular: "[...] quanto mais passivo (menos participativo) for o espetáculo, mais a cidade se torna um cenário, e o cidadão um mero figurante; e no sentido inverso, quanto mais ativo for o espetáculo [...], mais a cidade se torna um palco e o cidadão, um ator protagonista ao invés de mero espectador" (Jacques, 2005, p. 19). Como regra no Brasil, as cidades vêm se transformando em um simples cenário onde a população, em geral, tem cada vez menos influência na definição dos valores materiais e simbólicos, que determinam seu caráter de apropriação urbana e convivência social.

Esta ideia de "revitalizar" como meio de manter o controle do espaço público diante das dinâmicas da paisagem urbana, não é algo recente. Promover melhorias urbanas para garantir segurança e controle da sociedade e afastar a população mais pobre das áreas centrais, é uma realidade atuante desde as reformas urbanas na Europa, como foi o caso das intervenções em Paris, entre 1852 e 1870. A substituição da paisagem antiga pela promessa inovadora da modernidade definiu o modelo implantado pelo Barão GeorgesEugène Haussman (1809-1891) e serviu como referência para outras metrópoles ocidentais, na Europa e nas Américas, ao longo do século XX. Mesmo hoje, em pleno século XXI, este modelo de 
intervenção urbana, com a proposta de tornar a cidade mais funcional para o capital e menos propícia para as manifestações sociais, abre espaço para novos empreendimentos e expulsa contingentes populacionais que possuem menor influência política e econômica sobre as decisões administrativas do município (Harvey, 2015).

Entre os exemplos mais recentes de intervenção em áreas urbanas centrais, Tania Martínez (2012) nos apresenta o processo de transfomação do bairro La Merced, na Cidade do México. Segundo a autora, desde os anos de 1980 esta área comercial e histórica da capital mexicana vem passando por processos de reformulação urbana com a intenção de substituir as redes informais de sociabilidade e comércio por uma estrutura urbana formal e compacta, nos moldes das cidades europeias. Esse processo de mudanças não interrompeu as redes de comércio informal, do tráfico de drogas e da violência iminente, ao longo das últimas décadas, mas amenizam o impacto destas ações cotidianas no contexto de inserções sociais e urbanas. Apesar do governo não conseguir superar a ambivalência entre a legalidade e a ilegalidade nesta área central da cidade, as ações institucionais contribuem para salvaguardar a segurança pública e a preservação do patrimônico arquitetônico, ainda que a gentrificação seja contínua (Martínez, 2012).

Este processo de gentrificação, que afasta a permanência de classes sociais mais pobres para abrir espaço de ocupação das classes mais ricas, junto com o enobrecimento e estratégias de marketing urbano, representa uma tendência da política pública de invisibilizar as camadas sociais de menor capital econômico através de retóricas que prometem um paraíso social de diversidade, energia e oportunidades de desenvolvimento comunitário (Wacquant, 2010). Contudo, este movimento reflete intenções de especulação imobiliária e exploração do turismo pela insustentabilidade social e cultural, quando não compatibilizam "a participação de todos os atores que atuam em determinado espaço e sem a análise criteriosa da capacidade de suporte que o meio físico dispõe para receber um contigente humano" (Schussel, 2012, p. 105). 
No caso de Florianópolis, se houvesse real interesse de humanizar as intervenções na esfera pública, o ideal almejado deveria abarcar o conceito de "vitalização" urbana, que se caracteriza pela utilização destes espaços por moradores locais através de atividades diversificadas e não restritas aos interesses de especulação entre empresários e governantes.

De acordo com Paola Jacques (2005, p. 19), esta apropriação seria possivel por meio de três aspectos: "a participação, a experiência afetiva e a vivência dos espaços urbanos". A autora acredita que a cidade deve tornar-se um corpo, e será dessa relação entre o "corpo cidadão" e o "corpo urbano" que surgirá outras formas de apreensão do meio público.

Consideramos que este viés de "vitalização" exposto por Jacques (2005) se encontra vinculado ao conceito de "humanização" apresentado por Mara Santos Rodrigues (2013, p. 2), quando esta aborda que:

Vitalizando o espaço público com o intuito de uma (re)valorização do mesmo, este assume um papel fulcral no desenvolvimento da qualidade do espaço privado adjacente. Procura-se estabelecer uma forte relação entre forma, função e contexto urbano, reforçando o lazer, a oportunidade de ver, ouvir e sentir o espaço, por via da humanização da arquitetura.

Notamos que no caso da humanização da esfera pública, apresentado por Rodrigues (2013), o conceito também vincula os aspectos arquitetônicos e o âmbito dos interesses privados nos espaços adjacentes, compreendidos no contexto da vida cotidiana e, assim, relacionando grande parte da sociabilidade e fortalecendo as relações sociais. Sobre isso, Ana Margarida Soutinho (2012, p. 13) busca compreender estes espaços na atualidade, tendo em vista que grande parte da população passa mais tempo no ambiente de trabalho, o que torna necessário promover modificações e adaptações a fim de transformar os ambientes públicos em lugares versáteis, "oferecendo-lhes uma nova vida ao invés de se tornarem vazios urbanos". A ideia de "dar vida" interage e complementa-se com o conceito debatido anteriormente de "vitalização", a partir do qual tais ambientes adquirem certa corporificação, tornando-se um "organismo vivo". 
No que diz respeito à humanização, talvez seja possível afirmar que a palavra-chave para defini-la é "acessibilidade" (social e física), uma vez que no âmbito do espaço público espera-se a livre circulação e interação entre os cidadãos. Para garantir tal acessibilidade, Soutinho (2012) propõe o design inclusivo, que pressupõe projetos que visam à coesão social, evitando a projeção de espaços excludentes de determinados grupos, tais como aqueles que possuem algum tipo de limitação física, sensorial ou cognitiva.

A associação internacional de projetos para espaços públicos (Project for Public Space - PPS) apresenta uma relação gradual para compreender as características necessárias para compor os espaços humanizados. Observando a figura 4, no centro do gráfico está à ideia de "lugar" e, a partir dele, as características básicas se ramificam na ordem concêntrica: 1) sociabilidade, 2) usos e atividades, 3) acessos e ligações, 4) conforto e segurança. A partir de cada uma destas características básicas surgem seus elementos motivadores, articulando a complexidade de prerrogativas e associando sensações desejáveis com as necessidades humanas.

Aprofundando estas características de humanização, a sociabilidade [1] seria intrínseca aos espaços públicos, haja vista que neles se reúnem todos os tipos sociais de uma mesma cidade e, ainda que não haja contato direto entre eles, os ambientes se tornam democráticos à medida que cada cidadão apropria-se dele da forma que melhor lhe convém. O espaço se torna mais diversificado e enriquecido a partir dos usos e atividades ali desenvolvidas [2]. Tais atividades devem ser pensadas de acordo com o lugar e, nesse sentido, "deve-se proceder a uma análise dos usos existentes na zona e perceber quais as funções que o local precisaria (e ainda possui), de modo que haja uma compatibilização de usos" (Soutinho, 2012, p.23). Os acessos [3] seriam aqueles que proporcionam ao cidadão a liberdade de ir e vir, independente das limitações físicas, incluindo adequações nas vias para todos os meios de locomoção (pedestre, automóvel, bicicleta e transporte coletivo). As características de conforto e segurança [4] estão inteiramente relacionadas, pois é mais fácil o cidadão sentir-se confortável em locais seguros. 


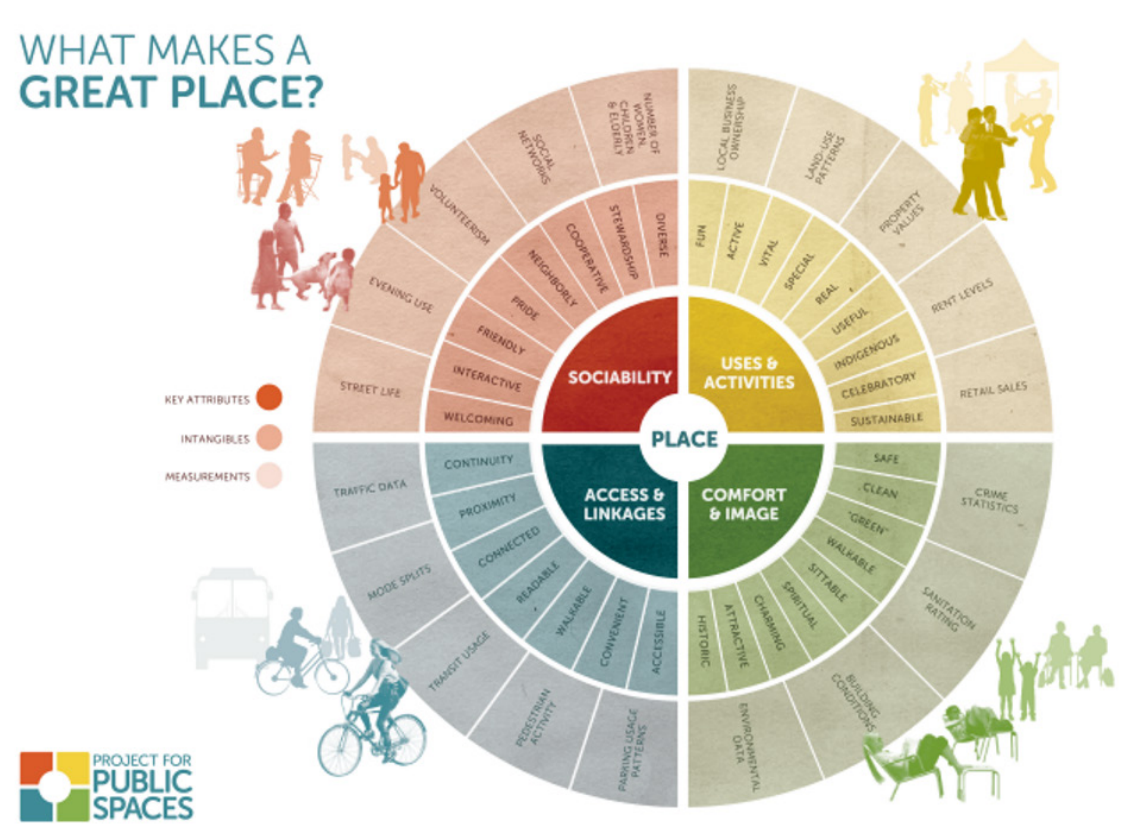

Figura 4. "O que faz um lugar ótimo?". Características do espaço humanizado Fonte: Project for Public Spaces.

Diante do que foi apresentado até aqui, nos parece claro que a revitalização ou o enobrecimento espacial está vinculado a espetacularização de locais históricos e de referência urbana, voltadas para os interesses de exploração comercial e turística. Nesse caso, a proposta de revitalização pode estar desvinculada, diretamente, do interesse da população que faz uso permanente do local, resultando em processos graduais de gentrificação.

Em contrapartida, a "humanização" (ou a "vitalização") possibilita transformar o espaço urbano e público em local propício à sociabilidade e a experiência direta do corpo social com o ambiente público, bem como, no desenvolvimento de atividades sociais e econômicas necessárias para manutenção dos estabelecimentos comerciais. Mas é importante ressaltar que o foco da humanização é a qualidade a ser proporcionada para as pessoas, indiscriminadamente. Situação diversa das propostas de 


\begin{abstract}
"revitalização" que se voltam aos interesses de oligarquias e refletem uma concepção de vida baseada na exclusão e no contraste social.
\end{abstract}

\title{
Considerações finais
}

Com este artigo não tivemos a pretensão de realizar uma análise generalizante dos processos de revitalização, mas buscamos trazer à tona a discussão de conceitos amplos e, por vezes, indistintamente utilizados por agentes públicos em seus discursos e projetos que envolvem espaços públicos.

A partir do breve resgate histórico a cerca da configuração urbana de Florianópolis, observamos que a acumulação de problemas, sobretudo na área que compreende o centro da capital, tem sido permanente devido à falta de propósito para os interesses coletivos e transparência no planejamento da cidade. As decisões que são tomadas para tornar a cidade mais funcional, mais atraente para o turismo e mais lucrativa para os especuladores, misturam-se entre decisões fragmentadas e intervenções superficiais que não alcançam as verdadeiras demandas para a implementação de recursos materiais e espaciais voltados para a experiência do cotidiano.

Nesse sentido, procuramos apresentar aqui a proposta de "revitalização" da área central de Florianópolis como mecanismo não permanente de consolidação de uma nova territorialidade urbana. A intervenção em questão faz uso de instrumentos efêmeros e sutis, alterando o ritmo das atividades locais, estimulando a circulação de um novo contingente populacional e, associando a melhoria na qualidade de vida da cidade pela transformação (em diferentes prazos) daquilo que é de domínio público para o domínio de incorporações privadas e coalizações do mercado imobiliário.

Tais medidas de planejamento representam uma gama de decisões politicas que definem a regra da heteronomia do planejamento urbano. Mesmo para uma área central, abandonada pelo planejamento e investimento 
públicos, existe um potencial a ser explorado pela informalidade urbana $\mathrm{e}$ como ponto de encontro de grupos e interesses diversos que não costumam adequar-se ao modelo padrão requeridos pelo "espaço gourmet".

Neste caso, o conceito de humanização apresentado neste artigo, diz respeito à possibilidade de (re)apropriação do espaço público sem estipular regulamentações para viver a cidade, considerando a inclusão de atividades culturais e de lazer e não excluindo as relações comerciais, de maneira a tornar possivel a experiência urbana com autonomia, entre diferentes ritmos e categorias de apropriação espacial.

\section{Referências}

Agostinho, MG. (2008). O Espaço Público Urbano e a Cidadania nas Cidades Contemporâneas: o caso do Parque da Luz em Florianópolis/SC (Tese, Programa Interdisciplinar em Ciências Humanas da Universidade Federal de Santa Catarina). UFSC, Florianópolis.

Camargo, ST. (2014). A recuperação do Centro Histórico de Florianópolis. Disponivel em http://floripamanha.org/2014/04/a-recuperacao-do-centrohistorico-de-florianopolis /

CDL Florianópolis. (2013). Viva a Cidade. Disponível em http://www. cdlflorianopolis.com.br/noticia/viva-a-cidade-2317

Costa, SS. (2011). Santa Catarina: história, geografia, meio ambiente, turismo e atualidades. Florianópolis: Postmix.

Frighetto, M. (2013). Dalmo Vieira Filho e os planos para humanizar Florianópolis. Disponivel em http://ndonline.com.br/florianopolis/noticias/98008-dalmovieira-filho-e-os-planos-para-humanizar-florianopolis.html

Goldner, LG. y Silva, DM. (2013). Análise da Mobilidade Urbana em Florianópolis com Ênfase no Transporte Público por Ônibus. $19^{\circ}$ Congresso Brasileiro de Transporte e Trânsito, Brasília. 
Harvey, D. (2015). Paris: capital da modernidade. São Paulo: Boitempo.

Jacques, PB. (2005). Errâncias urbanas: a arte de andar pela cidade. Revista Arqtexto, (7), 16-25.

Koerich Imóveis. (2017). A W Koerich Imóveis. Disponivel em http://www. koerichimoveis.com.br/a-koerich-imoveis.htmlLeite, RP. (2005). Patrimônio e consumo cultural em cidades enobrecidas. Revista Sociedade e Cultura, 8(2), 79-89.

Leite, RP. (2010). A exaustão das cidades: antienobrecimento e intervenções urbanas em cidades brasileiras e portuguesas. Revista Brasileira de Ciências Sociais, 25(72). Disponivel em http://www.scielo.br/pdf/rbcsoc/v25n72/ v25n72a06.pdf

Martínez, T.S. (2012). La informalidad en el barrio antiguo de La Merced. Algunas aproximaciones. En F. Alba y F. Lesemann(Coords.), Informalidad urbana e incertidumbre: ¿cómo estudiar la informalización en las metrópolis? (pp. 131-144). México, D.F.: Programa Universitario de Estudios sobre la Ciudad.

Meneses, UTB. (2000). Valor cultural, valor econômico: encontros e desencontros. In II Seminário Internacional de História da Energia de São Paulo. Potencial estratégico de cultura e negócios. São Paulo: Fundação Patrimônio Histórico da Energia de São Paulo.

Pimenta, MCA. (2005). Florianópolis como Espaço do Público. In MCA Pimenta (Org.), Florianópolis: do outro lado do espelho (pp. 35-60). Florianópolis: Editora da UFSC.

Portal, M.A. (2016). Espacios públicos diferenciados en la Ciudad de México. Una mirada desde el lugar. En A. Rosas Mantecón y F. Frehse (Coords.), Vivir y pensar São Paulo y la Ciudad de México: trayectorias de investigación en diálogo (pp. 83-107). México: Universidad Autónoma Metropolitana - Juan Pablos Editor.

Project for Public Spaces. (2009). What Makes a Successful Place? Disponivel em http://www.pps.org/reference/grplacefeat/ 
Rodrigues, MS. (2013). Arquitectura Genética. Estratégia para humanizar o espaço público. Seminário Internacional de Investigación en Urbanismo. Barcelona: DUOT.

Schussel, ZGL. (2012). Turismo, Desenvolvimento e Meio Ambiente. In MDS. Brasileiro, JCC. Medina y LN. Coriolano, (Orgs.), Turismo, Cultura e Desenvolvimento [online] (pp. 99-120). Campina Grande: EDUEPB. Disponivel em http://books.scielo.org/id/7y7r5/pdf/brasileiro-9788578791940-06.pdf

Sêga, R.A. (2000). Os Melhoramentos Urbanos como Estratégias de Dominação Social. Anos 90, (14).

Soutinho, A.M.M.S. (2012). Humanização do espaço público urbano (Dissertação, Departamento de Arquitectura, Ciências e Tecnologia. Universidade Católica Portuguesa, Portugal. Disponivel em https://repositorio.ucp.pt/ handle/10400.14/17482

Vaz, N.P. (1990). Reorganização da área central de Florianópolis: o espaço público do ritual (Dissertação, Programa de Pós-Graduação em Geografia). UFSC, Florianópolis. Disponível em http://repositorio.ufsc.br/xmlui/ handle/123456789/75642

Wacquant, L. (2010, jan.-abr.). Ressituando a Gentrificação: a classe popular, a ciência e o Estado na pesquisa urbana recente. Caderno $C R H, 23(58)$, 51-58.

\section{Cómo citar este artículo}

Perini, KP, Sardá, MV y Guivant, JS. (2018). Ausência de Humanização na "Revitalização" do Centro Histórico de Florianópolis, Santa Catarina, Brasil. Universitas Humanística, 85, 213-233. https://doi.org/10.11144/Javeriana. uh85.ahrc 